\title{
THE COBRA VENOM HEMOLYSIS TEST IN SYPHILIS, WITH REPORT OF ONE HUNDRED AND THIRTY REACTIONS *
}

\author{
WILLARD J. STONE, M.D., AND RICHARD SCHOTTSTAEDT, M.D. \\ TOLEDO, $o$.
}

\section{HISTORICAL}

Much of the early work on cobra venom hemolysis was done by Calmette, ${ }^{1}$ Stephens, ${ }^{2,3}$ Myers, ${ }^{2,}{ }^{4}$ Mitchell and Flexner, ${ }^{5}$ Flexner and Noguchi, ${ }^{6}$ Kyes, ${ }^{8,9}$ Sachs, ${ }^{9,}{ }^{10}$ Abderhalden and LeCount, ${ }^{11}$ and Goebel. ${ }^{12}$ Additional papers by Noguchi, ${ }^{7}$ von Dungern and Coca, ${ }^{13}$ Bang $^{14}$ and Weil ${ }^{15}$ have, within the past five years, created new interest in the subject. From the work of Kyes it has been shown that the incomplete hemolysin present in native cobra venom (amboceptor, as first suggested by Flexner and Noguchi) is activated, in the absence of serum, by complementing substances (lecithin) present in the red cells to form the complete hemolysin, called by him "cobra-lecithid."

*Manuscript submitted for publication April 3, 1912.

* Read at the meeting of American Association of Pathologists and Bacteriologists, Philadelphia, April 6, 1912.

1. Calmette: Ann. de l'Inst. Pasteur, 1892, vi; Compt. rend. Soc. de biol., 1894 ; Compt. rend. Acad. d. sc., 1902, exxxiv, 1446.

2. Stephens and Myers: Brit. Med. Jour., Mar. 5, 1898; Jour. Path. and Bacteriol., 1898, v, 279.

3. Stephens: Jour. Path. and Bacteriol., 1900, vi, 273.

4. Myers: Jour. Path. and Bacteriol., 1900, vi, 415; Trans. Path. Soc., London, Feb. 6, 1900 .

5. Mitchell and Flexner: Nat. Acad. Sc., 1901.

6. Flexner and Noguchi: Jour. Exper. Med., 1902, vi, 277; Univ. Penn. Med. Bull., 1902, xv, 345.

7. Noguchi: Jour. Exper. Med., 1907, ix, 436; Serum Diagnosis of Syphilis, Lippincott, Phila., 1911; Snake Venoms, Chap. xvi, Carnegie Institution, Washington, 1909.

8. Kyes: Berl. klin. Wchnschr., 1902, xxxix, 886; ibid., 1903, xlii, 21 ; ibid., 1903, xlii, 956; Biochem. Ztschr., 1907, iv, 109; Jour. Infect. Dis., 1910, vii, 181.

9. Kyes and Sachs: Berl. klin. Wchnschr., 1903, xlii, 21, 57, 82.

10. Sachs: Centralbl. f. Bact., 1903, xxxiv, 686; Biochem. Centralbl., 1906, v, 257 ; München. med. Wchnschr., 1908, lv, No. 9.

11. Abderhalden and LeCount: Ztschr. f. exper. Path. u. Therap., 1905, ii, 199.

12. Goebel: Compt. rend. Soc. de biol,, 1905, lviii, 420.

13. Von Dungern and Coca: München. med. Wchnschr., 1907, iv, 2317; ibid, 1908, Iv, 105; Biochem. Ztschr., 1908, xii, 407; Jour. Infect. Dis., 1912, x, 57.

14. Bang: Biochem. Ztschr., 1908, xi, 521.

15. Weil: Proc. Soc. Exper. Biol. and Med., 1909, vi, 49; ibid., 1909, vii, 2; Jour. Infect. Dis., 1909, vi, 688. 
COBRA VENOM REACTIONS IN SYPHILIS
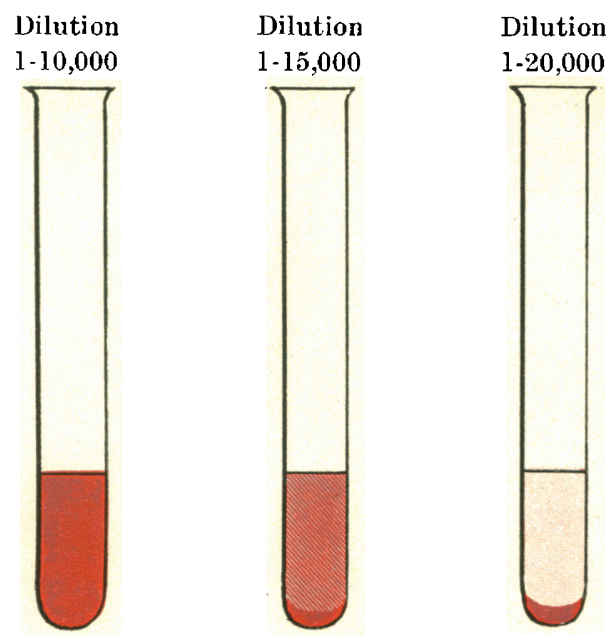

Dilution 1-30,000

Marked Positive
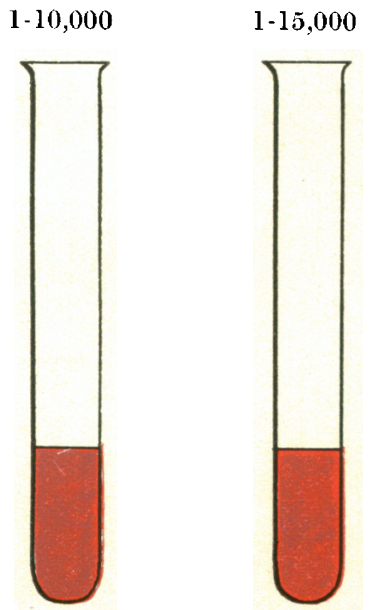

1-20,000

$1-30,000$

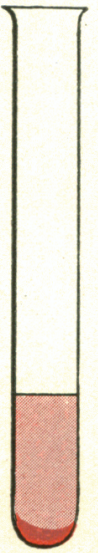

Positive
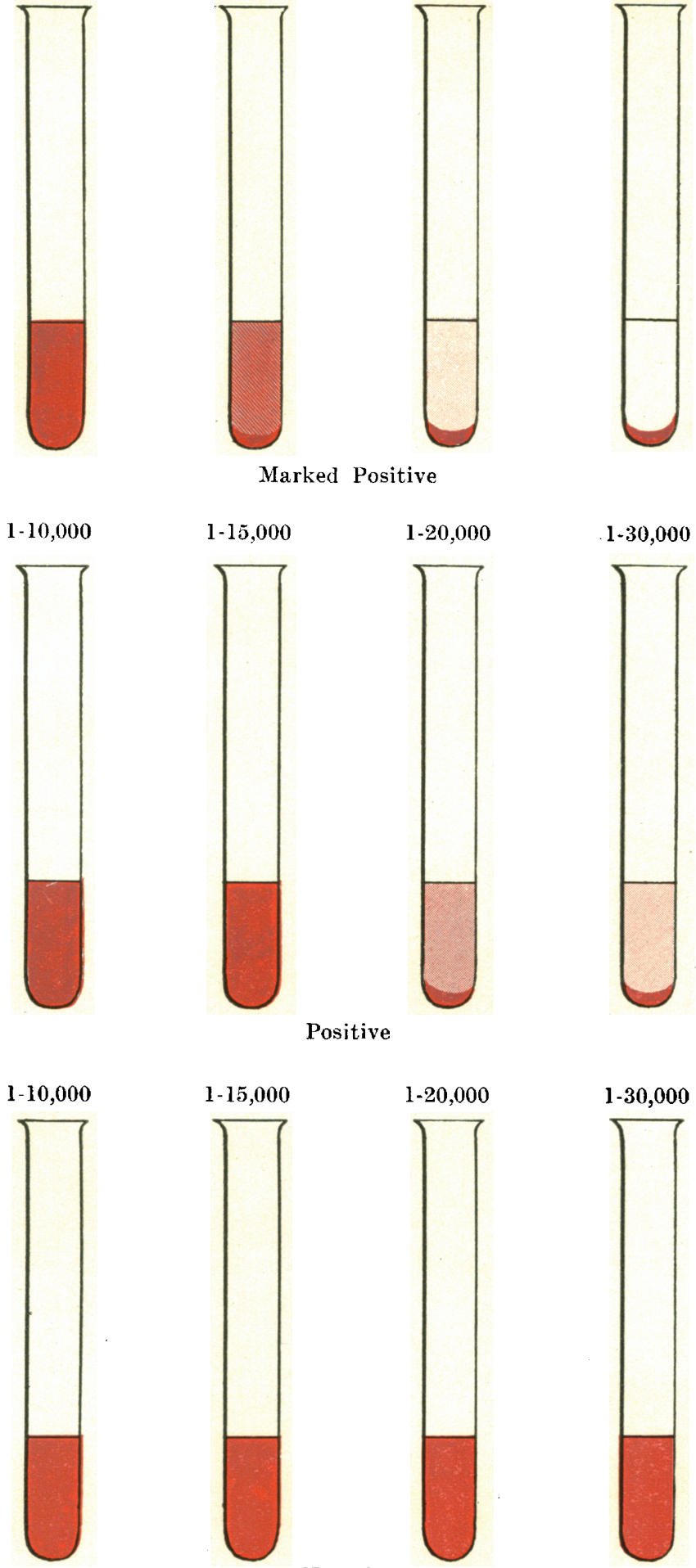

$1-20,000$

$1-30,000$
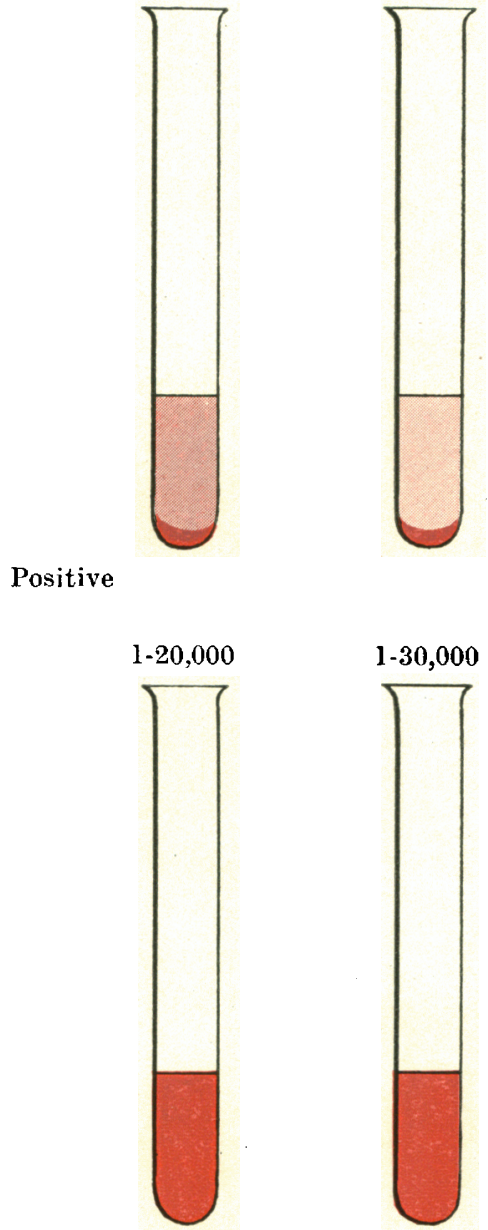

Negative 
According to Hober ${ }^{16}$ lecithin, with a small amount of cholesterin, is said to form 33 per cent. of the solid ingredients of red cells. Sachs has suggested that the hemolytic resistance of red cells, from different individuals of the same species, varied according to the amount of lecithin in the cells. Kyes, on the other hand, while substantiating in the main the results obtained by Sachs, believes that, since all erythrocytes contain sufficient lecithin to activate cobra venom, the varying susceptibility of red cells to the venom depends rather on the availability of the intracellular lecithin for the reaction. That is, whether the lecithin in its combination with the cell structure, is available in a free state.

Any factor, therefore, which modifies the availability of the cell lecithin may modify the susceptibility of the cells for hemolysis with cobra venom. Thus, the erythrocytes of sheep, ox, or goat, in physiological salt solution, which are never susceptible to cobra venom irrespective of the strength of solution employed, become highly susceptible to venom when the cells are suspended in physiological sugar solution. Also, certain lipoid substances, such as the.fatty acids, neutral fats and soaps of the fatty acids, possess certain powers, probably through modification of the cells, to render more available the intracellular lecithin for the formation of the complete hemolysin. Since these substances act through modification of the cells, indirectly affecting the availability of the contained lecithin, they are considered to be indirect activating agents. Chloroform, ether and bile salts fall into this class.

In susceptible cells, on the other hand, the union of cobra venom and lecithin occurs directly with the formation of the complete hemolysin, designated by Kyes cobra-lecithid, due to a splitting of the fatty acid radical from the lecithin. Lüdecke, ${ }^{17}$ von Dungern and Coca ${ }^{13}$ and Manwaring $^{18}$ have contended, however, that this product was a venom-free lecithin derivative and not a lecithid. They have preferred to call the active principle "cobralecithinase" and the hemolytic end-product, "monofatty-acid lecithin" or "desoleo-lecithin." Von Dungern and Coca do not believe that lecithin acts as a complement in the reaction.

In the study, however, of the behavior of cobra venom solutions and red cells, definite quantitative relations have been shown to exist between the strengths of solutions and the amounts of lecithin contained in the cells. As mentioned by Kyes, these results "are comparable to those given by Morgenroth and Sachs ${ }^{\mathbf{1 9}}$ for complement and amboceptor in hemolytic sera; viz., that within certain limits, the larger the amount of

16. Hober (Quoted by Schwartz): "Chemie der Zelle." Ed. 2, 1906.

17. Lüdecke: Inaugural Dissertation, München, 1905. (Quoted by Schwartz, N. Y. Med. Jour., 1912, xev, 23.)

18. Manwaring: Johns Hopkins Hosp. Bull., September, 1910; Ztschr. f. Immunitätsf., 1910, vi, 513 .

19. Morgenroth and Sachs: Berl. klin. Wchnschr., 1902, xxxix, 817. 
venom, the smaller the amount of lecithin required to effect hemolysis; and vice versa, the larger the amount of lecithin the smaller the amount of renom required." On the other hand, with a fixed amount of lecithin, an increase in the amount of venom beyond the usual requirements for hemolysis inhibits the lysis, since the quantitative relations between the substances have been disturbed, a condition analogous to the Neisser-

Table 1.-Specific Reactions in Luetics axd Controls

\begin{tabular}{|c|c|c|c|c|c|}
\hline 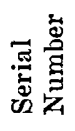 & Stage & $\begin{array}{l}\text { Duration, } \\
\text { Years }\end{array}$ & Wassermann & $\begin{array}{l}\text { Noguchi Butyric } \\
\text { Acid Test* }\end{array}$ & $\begin{array}{c}\text { Cobra Venom } \\
\text { Test }\end{array}$ \\
\hline 2. & Tertiary, active & 2 & + & .. & + \\
\hline 3. & Primary & $1 / 8$ & + & . & + \\
\hline 4. & Congenital, active & & + & $\because$ & + \\
\hline 11. & Secondary, active & $5 / 12$ & + & $\therefore$ & + \\
\hline 14. & Normal & .. & 二 & - & - \\
\hline 15. & Normal & .. & $\cdots$ & .. & - \\
\hline 18. & Psoriasis & .. & - & .. & - \\
\hline 20. & Clin. eured & & - & .. & - \\
\hline 40. & Secondary, active & $1 / 2$ & + & .. & + \\
\hline 46. & Tertiary, active & & - & .. & + \\
\hline 48. & Tabes, dorsalis & 3 & \pm & . & \pm \\
\hline $\begin{array}{l}50 . \\
53 .\end{array}$ & $\begin{array}{l}\text { Normal } \\
\text { Tertiary, active }\end{array}$ & $\ddot{5}$ & $\overline{+}$ & .. & $\bar{t}$ \\
\hline 62. & Tertiary, latent & $\dagger$ & $\ldots$ & + & + \\
\hline 63. & Normal & & .. & - & - \\
\hline 64. & Gen. paralysis & $\ddagger$ & . & + & + \\
\hline 65. & Tertiary, latent & 4 & + & + & + \\
\hline 69. & Gen. paralysis & $\ddagger$ & $\therefore$ & + & + \\
\hline 74. & Gen. paralysis & 7 & .. & $i$ & + \\
\hline 80. & Tertiary, active & 36 & & & + \\
\hline 81. & Gen. paralysis & $12-14$ & + & $\begin{array}{l}+ \text { in cerebro. } \\
\text { spinal fluid. }\end{array}$ & - \\
\hline 82. & Gen. paralysis & $\ddagger$ & + & + in cerebro- & + \\
\hline 83. & Cerebral syphilis & $\ddagger$ & $\begin{array}{l}+ \text { in cerebro- } \\
\text { sp in a I fluid. } \\
\text { Neg. in blood. }\end{array}$ & + in cerebro- & - \\
\hline 84. & Progr. bulbar palsy & .. & . & $\begin{array}{l}\text { - in cerebro- } \\
\text { spinal fluid. }\end{array}$ & - \\
\hline 86. & Chr. pulm. tubercu. & .. & . & 一 & - \\
\hline
\end{tabular}

*Blood-serum was used in making the butyric-acid test except in cases so designated.

† Lues denied. $¥$ Unknown.

Wechsberg phenomenon, in which an excess of amboceptor inhibits the action of a minimal amount of complement.

VENOM HEMOLYSIS IN SYPHILIS

The considerations above described, while interesting from a theoretic standpoint, did not produce results of a practical nature until the publications of Weil, who found in testing the hemolytic powers of cobra 
venom, with cells derived from different types of disease, that the red cells of luetic individuals offered increased resistance to hemolysis. It was demonstrated that normal erythrocytes, and erythrocytes derived from individuals with diseases other than syphilis, would undergo complete hemolysis in dilutions as high as 1 in 30,000 to 1 in 40,000 ; while luetic red cells showed little or no hemolysis in dilutions varying from 1 in 15,000 to 1 in 30,000 . Weil's conclusions based on the reactions obtained in 191 cases showed that this characteristic was especially true of advanced syphilis.

One of three explanations is available for the phenomenon: (1) Either the quantity of red cell lecithin is actually diminished in syphilis, after the primary stage, as a reactive phenomenon to the luetic toxin; or (2) the toxin so affects the stromata-holding lecithin as to render less of it available in a free state for the formation of the hemolysin, "cobralecithid" (Kyes) or "monofatty-acid lecithin" (von Iungern, Coca, Manwaring); or (3) a dissociation has taken place between lecithin and cholesterin in the red cells with inhibition of hemolysis by the latter substance.

Weil has ealled attention to the fact that syphilis attacks the lipoid constituents of body cells, since the amount of lecithin which can be extracted in syphilis is less than can be obtained from normal tissues. In explanation of the increased resistance of luetic red cells to cobra venom hemolysis, he has suggested that possibly the luetic toxin attacks the same cellular constituents as cobra venom in much the same way that the hypodermic injection of phenyl-hydrazine produces an increased red cell resistance to all hemolytic agents including cobra venom. Such a result is probably a reactive phenomenon of tolerance, for Weil has shown that repeated injections of such an hemolytic agent as saponin leads in rabbits to the production of red cells which show marked resistance to saponin hemolysis but to no other hemolytic agents. The first generations of cells were found to be hypersusceptible to the action of saponin but subsequent generations had acquired tolerance to it.

Such a phenomenon apparently occurs in the reaction of luetic red cells to cobra venom. For about five or six weeks after the primary lesion the red cells are hypersusceptible to cobra venom hemolysis in all dilutions. Subsequent generations of red cells after six or eight weeks (about the time of secondary manifestations) acquire tolerance and become resistant to this hemolytic agent. The phenomenon of acquired resistance to saponin hemolysis is different, however, from the reaction of luetic cells with cobra venom. In lues, the reaction occurs in response to the luetic virus, with subsequent increased hemolytic resistance, to a toxin of dissimilar origin. The acquired tolerance to saponin manifests itself against saponin alone. The increased resistance of luetic cells to the 
hemolysin of cobra venom is apparently the first instance of specific alteration of diseased body cells to an hemolytic agent.

Whatever may be the ultimate explanation, it is certain that the reaction is characteristic of certain stages of syphilis, for in no other condition or disease has the same degree of resistance been encountered.

THE COBRA VENOM TEST AND TECHNIC

We are indebted to Dr. Weil for two samples of cobra venom. One was obtained from Calmette of lille and the other from Coca. The two specimens, when tested in various dilutions with normal and specific bloods, were found to possess equal hemolyzing powers. It is probable that the strength of the dried venom does not vary, although preliminary titration against red cells of normal and Iuetic individuals will determine the hemolyzing strength of any sample.

The stock solution consists of

Dried cobra venom

0.9 per cent. solution $\mathrm{NaCl}$

$\begin{gathered}0.005 \\ 10.0\end{gathered}=1-2000$ dilution

This stock solution if stored in the ice chest, keeps for at least one week. From this stock solution the following dilutions are made, using separate clean pipettes for each dilution. All subdilutions are kept in the ice chest:

\section{SUB-DILUTIONS}

Solution "A"--1:10,000=l c.c. stock sol. plus 4 c.c. 0.9 per cent. $\mathrm{NaCl}$ sol.

Solution "B"-1:15,000=2 c.c. sol. "A" plus 1 c.c. 0.9 per cent. $\mathrm{NaCl}$ sol.

Solution "C"-1:20,000=l c.c. sol. "A" plus 1 c.c. 0.9 per cent. $\mathrm{NaCl}$ sol.

Solution " $D "-1: 30,000=1$ c.c. sol. " $B$ " plus 1 c.c. 0.9 per cent. $\mathrm{NaCl}$ sol.

The blood is drawn from one of the veins at the bend of the elbow with a 5 c.c. glass Luer syringe to which is attached an ordinary antitoxin needle with flexible rubber connection. The syringe should contain about 2 c.c. of a 2 per cent. solution of sodium citrate (free from air bubbles). The exact amount of citrate solution is unimportant. The needle is passed through the flame several times. A piece of rubber tubing is tied above the elbow tight enough to constrict the superficial veins, the patient being in the prone position. The arm is cleansed with alcohol, and the needle inserted into the vein. The blood flows into the citrate solution in the syringe and, from its own pressure, gradually pushes the piston upward. When about 2 c.c. of blood has flowed into the syringe, the rubber constriction is loosened. Pressure with a compress of cotton is made over the point of the needle to prevent a hematoma, and the needle quickly withdrawn. The blood solution is then expelled into a 15 c.c. graduated centrifuge tube, and placed in the ice-box until ready for use (if necessary for 24 hours).

20. a. If the stock solution (after a suggestion by Schwartz) is divided into ten parts of 1 c.c. each and the tubes placed in a wide-mouthed, well-corked vacuum bottle containing salt and ice and kept frozen in the ice-chest, the strength of the venom solution remains unchanged. This procedure prevents waste of the venom solution. Since 1 c.c. of the stock solution is sufficient for two complete test series of subdilutions, $1 \mathrm{gm}$. of cobra-venom is sufficient for 4,000 tests. The wide-mouthed vacuum bottle may be obtained from $E$. Machlett. \& Son, 143-147 East Twenty-Third Street, New York. b. If the dried venom crystals are pulverized in a mortar with benzene (after a suggestion by Weil) and the benzene evaporated, a homogeneous powder results which is easier to weigh and to dissolve. c. We have modified the technic suggested by Weil for purposes of simplification. 
One should avoid shaking the cell suspension. When ready for use any clots which have formed on the bottom of the tube are first fished out with a platinum wire and the supernatant citrate solution removed with a capillary pipette. The tube is then filled with a 0.9 per cent. solution $\mathrm{NaCl}$, and centrifuged at moderate speed until the solution is clear (for 10 minutes). The salt solution is pipetted off and the process repeated three times more to remove all serum which, at least in some instances, inhibits hemolysis. Of the washed cells 0.6 c.c. should remain in the tube and 0.9 per cent. $\mathrm{NaCl}$ sol. added to 15 c.c. (a 4 per cent. suspension). In order to secure the same density of packed cells in the tube, it is necessary to centrifuge for a definite number of minutes. It is important to have the red cell suspension accurately made in order to secure uniformity in a series of tests. When ready for use, the red-cell suspension is gently shaken, once or twice, to secure even distribution of cells. One c.c. cell suspension is then added to 1 c.c. of renom dilutions; $1: 10,000 ; 1: 15,000 ; 1: 20,000 ; 1: 30,000$. The tubes are covered with tin foil and placed in the incubator for one hour at $37 \mathrm{C}$. The tubes are then gently shaken and placed in the ice-box over night when they are again gently shaken, and the readings taken one hour later. The $1: 10,000$ tube is used as a control on the dilutions of venom, since practically all human bloods will hemolyze in dilutions of 1 to 10,000 . If hemolysis should occur in higher dilutions and not in the 1 to 10,000 tube, pointing to discrepancy in technic, fresh solutions should be made and the test repeated. The readings are marked as follows:

$++=$ Complete hemolysis.

$+=$ Incomplete or partial hemolysis.

- = Hemolysis absent.

Practically all bloods will hemolyze in dilution $1: 10,000$ and all normal bloods in dilution $1: 15,000,1: 20,000$ and $1: 30,000$. If no hemolysis occurs in $1: 15,000$, in $1: 20,000$ and $1: 30,000$ tubes the result is strongly positive; if com. plete hemolysis occurs in dilutions $1: 10,000$ and $1: 15,000$, but none in $1: 20,000$ and $1: 30,000$ the result is positive. If complete, or almost complete, hemolysis occurs in all dilutions ineluding $1: 20,000$ and $1: 30,000$, the result is negative (see plate). If complete hemolysis occurs in all dilutions within one hour after their removal from the incubator, the cells are regarded as hypersusceptible to cobra venom. Hypersusceptibility occurs as a rule in syphilis until the fifth or sixth week after the primary lesion, and in tuberculosis when in an active stage.

\section{REMARKS ON THE TECHNIC}

It seems certain that sodium citrate plays an essential part in the reaction, for we have been unable to obtain satisfactory results without it. In fact, defibrinated blood hemolyzes in the dilutions concerned in the test within twenty-four hours regardless of the presence or absence of syphilis. In addition, if citrate solution is added to defibrinated blood, the hemolysis is retarded in the case of luetic blood and increased in tuberculous blood in a manner similar to that which occurs when blood is drawn into the citrate solution. The presence of fibrinogen or fibrin evidently has nothing to do with the reaction, and although lecithin is present in the blood plasma, it is probably not present as such in a free or available state. An appreciable amount of serum does not apparently retard the hemolysis. 
Table 2.-Cobra Venom Hemolysis in Lues as Affected by Treatment

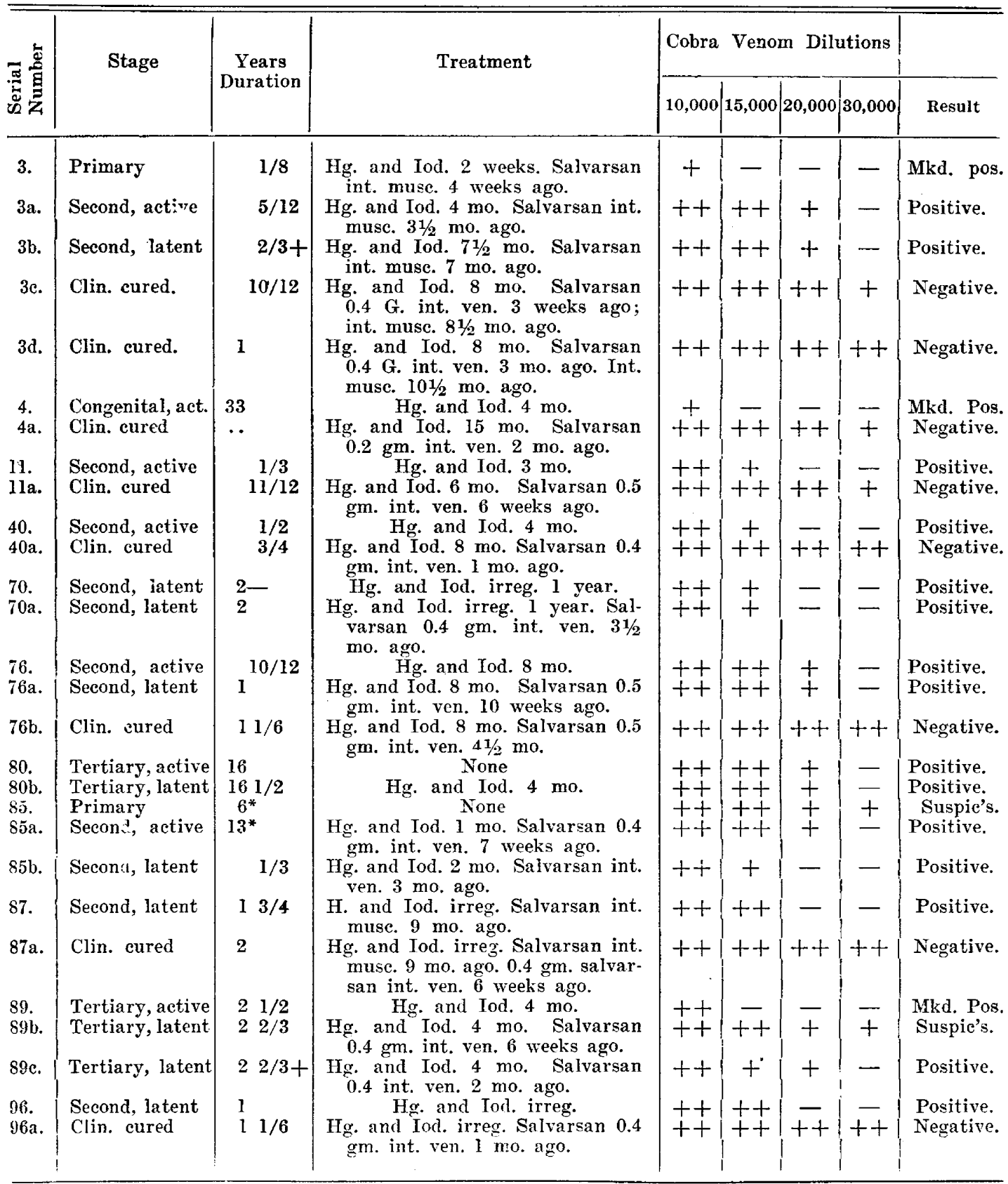

${ }^{*}$ Weeks. 


\section{CLINICAL DIAGNOSIS}

In the earlier part of our work the complement fixation method of Wassermann was used as a control, in a limited number of cases. The readings and results were practically parallel. The list of tests with normal blood and bloods from individuals with no clinical evidences of lues, but with other diseases, shows a negative result in all except in one patient with morbilliform erythema. This brings us to the point of interpretation of results. It may be taken for granted that each clinician, according to his experience, makes the mental reservation when obtaining the essential points in the history of a patient, whether such a patient, before further examination, is to be classed as (1) surely luetic, (2) probably luetic, or (3) probably non-luetic.

In the diagnosis of duodenal ulcer, for example, a careful history is often of more aid than the clinical findings, while in the clinical diagnosis of latent syphilis, a careful history dealing with the sequelæ of each year subsequent to the date of the supposed infection is most essential. Patiente are so often told after a cursory examination that an earlier small erosion had no significance. Likewise because of a neisserian infection the possibility of a coexistent hunterian chancre is many times forgotten. Such incidents are not rare, nor are extragenital primaries uncommon. On the other hand, little importance can be attached to the patients' statements as to the absence of sequelæ following a suspected lesion. Many of the manifestations of the disease may have been present, but their absence from the patient's point of view does not exclude syphilis.

The longer one works with specific tests the more impressed does one become with the varied manifestations and effects of the disease. In fact, as Cabot has stated, "anyone may have syphilis and be innocent of it." The remote effects of the disease, in whatever form, are so numerous and varied as to keep every clinician on his guard. This is particularly true of the congenital forms. In fact, the symptomatology of congenital and latent lues is as varied from a clinical standpoint as the colors of Joseph's coat. A considerable portion of so-called mentally deficient children suffer from congenital syphilis (36 per cent. of fortynine cases, Corson-White and Ludlum ${ }^{21}$ ). Also a fairly large proportion of apoplectic seizures in comparatively young individuals (under 40), if chronic nephritis and valvular disease can be excluded, are on a Inctic basis.

Likewise in many cases of so-called spontaneous or idiopathic epilepsy developing after the age of 15 , lues plays an important rôle. Such an instance was found in Case 80 of this series. The epileptiform seizures developed at the age of 21 , six years after an ignored and forgotten

21. Corson-White and Ludlum: Jour. Nerv, and Ment. Dis., 1910, xxxvii, 721. 
primary, coincidental with neisserian urethritis. These attacks had recurred at intervals of one month for ten years. The cobra venom test was positive on two occasions and the blood serum contained a markedly increased globulin precipitate, using the method described by Noguchi ${ }^{7}$ for cerebrospinal fluid. It was not considered advisable to do lumbar puncture on the patient. Since the inauguration of antisyphilitic treatment four months ago, no attacks have occurred.

We have on numerous occasions found it interesting to test the blood serum for increased globulin, instead of the cerebrospinal fluid, according to the method described by Noguchi for the latter. ${ }^{22}$ It does not appear necessary to use the more complicated method described by him for blood serum, since the globulin increase in syphilis, if present at all, seems to affect as distinctly the blood serum as the cerebrospinal fluid, and the simpler test often suffices. It is probably better, however, when possible, to test, in addition, the cerebrospinal fluid for increased globulin, by the butyric acid method of Noguchi, in any suspected form of cerebrospinal syphilis. If cerebrospinal fluid is used, the test is frequently positive in cerebral syphilis and general paralysis, although it may also be positive in tuberculous meningitis and acute meningitis from other causes. The test is negative in the psychoses, in cerebral arteriosclerosis, in brain tumor other than gumma, and in non-inflammatory meningeal irritation.

In the experience of Corson-White and Ludlum, "the globulin increase constantly accompanies primary, secondary and tertiary syphilis, tabes and paresis. In paresis the test is strongly positive in the blood and cerebrospinal fluid, while in cerebrospinal lues and tabes, increased globulin is a much more constant symptom than the complement fixation test. The non-specificity of the globulin test detracts from its diagnostic importance but not from its corroborative value, for the absence of the butyric acid reaction is more proof of the absence of syphilis than the absence of the Wassermann reaction. In tertiary syphilis of the nervous system the butyric acid test was positive in 94 per cent., the Wassermann in 67 per cent., while the cobra renom test was positive in only 22 per cent."

Corson-White ${ }^{23}$ has recently stated that in syphilis of the central nervous system, general paralysis and tabes (598 cases) the Wassermann test was positive in 82.5 per cent., the cobra test in 33.3 per cent.

22. To 1 c.c. of a 10 per cent. solution of pure butyric acid in physiological salt solution, in a test tube, 0.2 c.c. of blood serum or cerebrospinal fluid is added. The mixture is heated to boiling, 0.2 c.c. of normal sodium hydrate is added and the mixture again boiled. In the presence of increased globulin a definite floceu. lent precipitate occurs, either immediately or within an hour or two. This precipitate must be differentiated from a faint cloudiness which normal sera may give, but it requires only slight experience to differentiate between positive and negative reactions.

23. Corson-White: Personal Communication. 
THE INTERPRETATION OF HEMOLYSIS TESTS

It has proved instructive from many points of view to attempt to correlate the clinical history before an hemolysis test with the subsequent findings. In fact, in satisfying one's self as to the value of any method, it is essential to know with some degree of accuracy what is expected in order to interpret results. This is especially true in considering the necessity for further treatment. An hemolysis test is but one of the links in the chain of evidence. It is therefore believed that better results may be expected if the clinician on whom devolves the responsibility of diagnosis and treatment has, under his supervision, the details and control of such tests and a thorough understanding of the technic.

For example, it has been noted by many workers that tabetics and patients with general paralysis may not give positive hemolysis tests for lues. Such results should not necessarily militate against the tests or, for that matter, against the luetic origin, since these conditions may be only the effects of the earlier, perhaps sufficiently treated, disease. In fact, it is entirely possible, as suggested by Weil, that the luetic toxin makes selective action and that when it attacks the lipoid or lecithin constituents of the central nervous system, it spares these constituents of the red cells. This explanation is entirely plausible, for we are not without examples of the selective action of bacterial toxins in other types of infections.

\section{ADVANTAGES OF THE COBRA VENOM HEMOLYSIS TEST}

It may seem unnecessary to provide another test for syphilis, but because of certain advantages possessed by the venom test over others in vogue, it may not be out of place to lay stress on its important features. Probably the largest number of tests with this reagent has been made by Corson-White, ${ }^{23}$ who has stated that 2,078 cases have been examined. This number included syphilis in all stages (836 cases), controls, cancer, tuberculosis, brain tumors, sarcomata, typhoid, etc. She obtained positive cobra venom tests in 96.2 per cent. of frank visceral and bone syphilis, excluding cerebrospinal lesions. In latent (non-active) cases the results of the test were better than with the Wassermann or the Noguchi modification. She has also found that the test lasts longer in treated patients than other hemolysis tests.

Schwartz ${ }^{24}$ found, in early cases with little or no treatment. that the complement-fixation test was more sensitive than the cobra-venom test. An average of his figures for the early cases gave 86.9 per cent. positive reactions for the former, and 65.5 per cent. positive reactions for the latter. He found, however, in the later untreated stages of the disease, that the Weil test was more sensitive than the Wassermann.

24. Schwartz: New York Med. Jour., 1912, xcv, 23. 
For the late active cases with little treatment, the Wassermann was positive in 77.5 per cent., the Weil in 81.6 per cent. In the late, non-active, untreated cases, the Wassermann was positive in only 34.7 per cent., while the Weil was positive in 76.3 per cent. In nine of the cases reported by Schwartz, there was a definite history of lues and the Wassermann reaction was negative although the Weil test was positive, which shows that the latter test is more sensitive in certain old cases of syphilis.

Table 3.-Comparison of WassermanN and Well Reactions in active and LATENT SyPhilis

\begin{tabular}{|c|c|c|}
\hline \multicolumn{3}{|c|}{ POSITIVE WASSERMANN REACTIONS } \\
\hline & $\begin{array}{l}\text { Active Syphilis } \\
\text { Per cent. }\end{array}$ & $\begin{array}{l}\text { Latent Syphilis } \\
\text { Per cent. }\end{array}$ \\
\hline 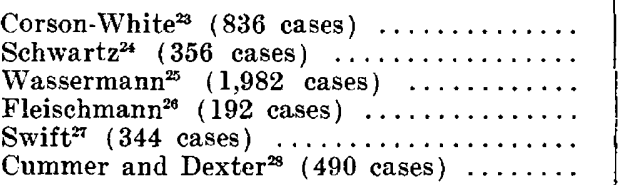 & $\begin{array}{l}88.5 \\
81.5 \\
90.0 \\
93.0 \\
87.5 \\
90.9\end{array}$ & $\begin{array}{l}51.7 \\
42.0 \\
50.0 \\
52.0 \\
54.1 \\
62.8\end{array}$ \\
\hline Average per cent., 4,200 cases $\ldots \ldots \ldots$ & 88.5 & 52.1 \\
\hline \multicolumn{3}{|c|}{ POSITIVE WEIL REACTIONS } \\
\hline & $\begin{array}{l}\text { Active Syphilis } \\
\text { Per cent. }\end{array}$ & $\begin{array}{c}\text { Latent Syphilis } \\
\text { Per cent. }\end{array}$ \\
\hline $\begin{array}{l}\left.\text { Corson-White }^{23} \text { ( } 836 \text { cases }\right) \quad \ldots \ldots \ldots \ldots \ldots \\
\text { Schwartz }^{24}\left(\begin{array}{l}356 \text { cases }) \\
\text { Stone and Schottstaedt }(87 \text { cases })\end{array} \ldots \ldots \ldots\right.\end{array}$ & $\begin{array}{l}96.2 \\
69.3 \\
90.9\end{array}$ & $\begin{array}{l}80.4 \\
66.1 \\
87.8\end{array}$ \\
\hline Average per cent., 1,279 cases $\ldots \ldots \ldots$ & 85.4 & 78.1 \\
\hline
\end{tabular}

It has been the experience of those who have worked with the cobra venom hemolysis test in lues, that the test is more sensitive and persists much longer than the Wassermann in treated patients. In fact, it is not at all unusual for a positive Wassermann to become negative after a short course of treatment. We have been convinced personally that many of the patients who a few years ago were pronounced cured, because of the absence of symptoms following faithful mercurial treatment for two or three years, were not cured at all but were merely in the latent tertiary stage of the disease. Many of these would give a positive reaction to either the Wassermann or the Weil test, and a considerable proportion would give a positive Weil reaction and a negative Wassermann.

25. Wassermann: Quoted by Bolduan, "Immune Sera," 1911, p. 198.

26. Fleischmann: Quoted by Bolduan, "Immune Sera," 1911, p. 197.

27. Swift: The Archives Int. Mfd., 1909, iv, 376.

28. Cummer and Dexter: Ohio State Med. Jour., Dec. 15, 1911. 
As mentioned by Corson-White and Ludlum, ${ }^{21}$ the number of positive responses to any specific test in tertiary syphilis falls very markedly from the number of responses given during the secondary period, although the results are positive in higher proportion in active tertiary than in latent tertiary syphilis. Such we have found to be the case with the cobra venom test. Figures, however, are apt to be misleading, since it is often exceedingly difficult, if not impossible, to tell whether a patient is afflicted with active tertiary or non-active (latent) syphilis without an hemolysis test. Much depends on the definition existing in the mind of the examiner. We have found the following classification satisfactory, and as such it has been used in the tables.

1. Primary.

2. Secondary. a. active.

b. non-active (latent).

3. Tertiary.

a. active.

b. non-active (latent).

4. Congenital.

a. active.

b. non-active (latent).

5. Clinically cured.

We have considered all patients with symptoms, such as universal glandular enlargements, mucous patches and roseola as secondary types even though the primary lesion was unhealed. When, after a few weeks or months, such secondary manifestations had disappeared and no symptoms were present, we have classed the type as secondary non-active (latent). If, after a quiescent period varying from a few months to years, symptoms again manifested themselves, we have classed the stage of disease as active tertiary; while if a lapse of a number of years occurred without active symptoms, we have classed the stage of disease as latent tertiary, if the hemolysis tests were positive, or clinically cured if such tests were regative.

The cobra venom test has proved much less laborious and timeconsuming in our hands than the complement fixation test of Wassermann, the final readings as clearly cut and the possibility of error less frequent. In a number of instances the test was repeated two or three times on the same patient before beginning treatment, and the final readings were found to be remarkably constant. In fact, on only two or three occasions have the final readings been classed as doubtful. and the tests have not, when full consideration was given to the clinical aspects of the cases, led, to our knowledge, to error in interpretation. On the contrary, a positive Wassermann reaction may lead to confusion in diagnosis. The blood of one patient with erythema multiforme gave positive complement fixation tests made by a colleague, and a negative cobra hemolysis test by ourselves. In this instance the Wassermann test was 
positive twice out of three times. The rash disappeared on free purgation and as the patient has subsequently been under observation for seven months, lues can be absolutely excluded.

The cobra test, however, was positive, in our hands, in another patient with morbilliform erythema but did not lead to confusion in diagnosis as other clinical evidences of lues were lacking. Again, in a patient with the clinical history and glandular evidences of pseudoleukemia, the blood gave a positive complement fixation test made by a colleague, while the cobra venom test was negative.

This patient because of the positive complement fixation test was given $0.6 \mathrm{gm}$. salvarsan intravenously by the attending physician. $\mathrm{He}$ developed an edema of the larynx, abundant nucleo- and serum-albumin appeared in the urine, which persisted until death, and the glands rapidly disappeared, as often happens under large doses of any form of arsenic. The glands, however, after a quiescent period of about ten days enlarged again and soon reached their former size. The enlargements persisted until death about ten weeks later, despite vigorous mercurial treatment. It is, of course, possible that this patient had coexistent lues (congenital?) and pseudoleukemia.

\section{CONTROLS}

The presence of jaundice has been supposed to interfere with the complement fixation test, but does not, so far as known, interfere with the cobra venom test. Schwartz obtained a positive Wassermann and a negative Weil test in a case of jaundice. Scleroderma, leprosy, polycythemia and scarlet fever have repeatedly given positive complement-fixation tests for lues by competent observers. We have had no opportunity to use the cobra venom test in such cases, but in Weil's reports he mentions negative cobra venom tests in six cases of scarlet fever, two of polycythemia and one of scleroderma. Schwartz, however, obtained positive cobra venom tests in one patient with scleroderma and in another with Raynaud's disease, both of whom gave negative Wassermann tests. He mentions that both these conditions are looked on by many as of luetic origin and that the Wassermann test has frequently been reported as positive in both.

In 129 patients sent to him for diagnosis it was found that the Wassermann and Weil reactions agreed in 124, or 96 per cent. He also found in the examination of seventy-five control patients with various diseases including cancer, tuberculosis, pernicious anemia, pneumonia, erythema multiforme and other skin diseases, chancroid, osteomyelitis, periostitis, acute arthritis, hepatic cirrhosis, leukoplakia, scleroderma and sarcoma that all were negative to both tests. In three other patients with advanced carcinoma, in which the Wassermann reaction was negative, Schwartz obtained positive cobra venom tests. Weil has mentioned a positive cohra venom reaction in a patient with gastric carcinoma who subsequently confessed to a syphilitic infection twenty years previously. 
Schwartz obtained a negative Wassermann and a positive Weil reaction at the first examination of a patient with Addison's disease. After two weeks of luetic treatment, during which time the patient improved, both tests were positive. The patient probably had a syphilitic affection of the suprarenals.

\section{SUMMARY}

In four patients with primary syphilis the cobra reaction was positive in only one, or 25 per cent.

In twenty-two cases of active secondary and tertiary syphilis the cobra venom reaction of Weil was positive in twenty, or 90.9 per cent. Of the two which did not give positive reactions, one was negative, while the other gave a "suspicious" reaction. The latter patient had been on mixed treatment for five years with two recent injections of salvarsan. If the test had been made two months, instead of two weeks, subsequent to the last injection of salvarsan the test would, in all probability, have been negative and he would have been classed with the "clinically cured."

In thirty-three cases of latent secondary and tertiary syphilis the cobra venom reaction of Weil was positive in twenty-nine, or 87.8 per cent. Of the four which did not give positive reactions, two were negative and two gave "suspicious" reactions. Both of the latter had had mixed treatment for more than one and one-half years with no recent active clinical signs of the disease. They would, under ordinary conditions, have been classed with the "clinically cured."

In twenty clinically cured patients the cobra reaction was negative in all.

At this point we wish to call attention to the figures shown in Table 3. It will be noticed that the average positive Wassermann reactions, as obtained in an analysis of 4,200 cases of active syphilis was 88.5 per cent., while the average positive Weil reactions in 1,279 cases of active syphilis was 85.4 per cent. The two averages are approximately the same. On the other hand, there is a marked difference between the averages, similarly obtained, for latent syphilis. The Wassermann positives in latent syphilis averaged 52.1 per cent., while the Weil positives in latent syphilis averaged 78.1 per cent.

In other words the Weil cobra venom test lasts longer in treated cases than the Wassermann and has given about 26 per cent. more positive responses in latent syphilis than the Wassermann. Such a result is of especial value in the latent stage of the disease when clinically the diagnosis is, for the most part, obscure, and when a laboratory test is most needed to supplement clinical opinion.

In seventeen cases of syphilis, normals, parasyphilis and other diseases (Table 1) the Wassermann and Weil reactions agreed, when blood was used, in fifteen, or 88.2 per cent. One of these was a tertiary active in which the Wassermann reaction was negative while the Weil 
test was positive; the other was a case of general paralysis, probably on a luetic basis, with positive Wassermann reaction in blood serum, positive increased globulin test in cerebrospinal fluid and a negative Weil reaction.

In thirteen cases of syphilis, normals, parasyphilis and other diseases, the Weil and Noguchi butyric acid reactions agreed in eleven, or 85.4 per cent.

In our work with forty-three controls a negative Weil reaction was obtained in all but one, a patient with morbilliform erythema.

Fourteen of the controls were patients with tuberculosis in an active stage. In twelve of the fourteen, complete hemolysis took place very rapidly in all tubes in about three hours as contrasted with about twentyfour hours for normal blood. The two bloods which did not hemolyze so rapidly were from patients who confessed to syphilis in earlier years.

In contrast, then, to the hyposusceptible cells of luetic individuals to cobra venom hemolysis, the cells of individuals in an active stage of tuberculosis are apparently hypersusceptible to cobra venom hemolysis. The tubercle toxin appears to so affect the stromata-holding lecithin of the cells as to render it more freely available for the union with cobra venom, the exact opposite of which apparently occurs as a result of the action of the luetic toxin on the lecithin of red cells. This suggestion may be of value in differentiating syphilis and tuberculosis of the lungs in which the clinical diagnosis might not otherwise be clear. Such an instance occurred in Patient 109, who had been under treatment in the dispensary for two years for pulmonary tuberculosis which was supposed to have followed pneumonia eight years before. Tubercle bacilli had never been demonstrated nor had the temperature been above 99 degrees, although signs of pulmonary excavation were present. Lues was denied but the patient improved rapidly under specific treatment.

Addendum: Since this article was completed Kuschakoff, ${ }^{29}$ working under the direction of Wassermann, has published his comparative results in a series of patients tested with the complement fixation method and the cobra reaction. He concludes that "the phenomenon of retarded hemolysis is present in a considerable portion of cases with syphilis but the cobra reaction is of no practical value unless controlled by the Wassermann reaction." As will be evident from his own figures, such conclusions are not warranted, for in sixty-seven cases of undoubted syphilis only twenty-eight gave a Wassermann positive while thirty-two gave a cobra positive; i. e., 41 yer cent. as against 48.5 per cent. In Table 6 of his article he has stated that of fifteen patients infected with syphilis eight to twelve years previously, four were Wassermann positive and eleven were Wassermann negative, while nine were cobra positive and six were cobra negative; i.e., 26.6 per cent. Wassermann positive as against 60 per cent. cobra positive. In eight of his patients who had received intensive treatment the cobra reaction was positive while the Wassermann reaction was negative. In twenty-one controls the cobra reaction was negative in all. It therefore seems far-fetched to describe the Wassermann as a necessary control to the cobra test since his own figures entirely disprove his assertions.

216 Colton Building.

29. Kuschakoff: Ztschr. f. Immunitätsf., 1912, xii, 532. 